\title{
Parachute Technique for Head and Neck Free-Flap Inset
}

\author{
Se Hyun Yeou, Yong Jae Song, Ju Ho Lee, and Yoo Seob Shin (DD \\ Department of Otolaryngology, School of Medicine, Ajou University, Suwon, Korea
}

\section{패러슈트 기법을 이용한 두경부 결손 내 유리피판 삽입}

여세현 · 송용재 · 이주호 · 신유섭

아주대학교 의과대학 이비인후과학교실

\author{
Received July 13, 2021 \\ Revised August 11,2021 \\ Accepted August 11, 2021 \\ Address for correspondence \\ Yoo Seob Shin, MD, PhD \\ Department of Otolaryngology, \\ School of Medicine, \\ Ajou University, \\ 164 Worldcup-ro, Yeongtong-gu, \\ Suwon 16499, Korea \\ Tel $+82-31-219-5262$ \\ Fax $+82-31-219-5264$ \\ E-mail ysshinmd@ajou.ac.kr
}

The treatment outcome of advanced squamous cell carcinoma involving the head and neck is well known to be dire and usually needs multimodality treatment even including optimal reconstruction after ablative surgery. When a significant area of the soft tissue is resected, reconstruction of oral cavity or pharynx needs to minimize morbidities while achieving adequate functional outcomes. For the better functional outcome, invasive approaching procedures such as lip and jaw splitting, or extensive floor of mouth or pharyngeal muscle ablation should be avoided. Without these surgical procedures, reconstructive surgeons may encounter technical difficulties in flap inset due to deep and narrow space after head and neck cancer resection. In a deep and narrow surgical defect, accurate approximation and suture is extremely difficult. Eventually, repeated flap manipulation and stretch might be inevitable, and even pedicle kinking or injury could happen. Herein, we suggested the "parachute" technique, which was generally used in blood vessels or aortic valve suturing in a narrow surgical field and for avoiding mismatched suture. We applied this "parachute" technique for free-flap inset to head and neck defect, and we herein report our successful outcomes.

Korean J Otorhinolaryngol-Head Neck Surg 2021;64(9):684-6

Keywords Free-flap; Head and neck cancer; Inset; Parachute technique.

\section{서 론}

두경부의 재건수술을 시행할 때에는 여러가지 인자들을 고 려해야 한다. 두경부암을 절제한 후 재건은 공여부위나 수혜 부위의 회복이 빨리 이루어질 수 있어야 하며, 종양을 절제하 고 나서 발생하는 3 차원적 구조를 가지는 결손을 적절하게 복원해야 기능적으로 연하, 발성, 흡인방지 등 복잡한 기능을 보존할 수 있다. ${ }^{1)}$ 성공적인 재건을 위해 두경부의 다양한 생 리적 기능과 특성을 이해하고 이를 최대한 보존하며 기능을 유지할 수 있어야 한다. ${ }^{2)}$ 진행된 두경부암의 경우 종양을 안 전하게 노출하기 위해 하악/하순을 절개하거나 구강저 혹은

This is an Open Access article distributed under the terms of the Creative Commons Attribution Non-Commercial License (https://creativecommons.org/licenses/by-nc/4.0) which permits unrestricted non-commercial use, distribution, and reproduction in any medium, provided the original work is properly cited.
인두를 구성하는 근육을 절개하는 술식이 필요할 수 있다. 또한 이러한 술식은 적절한 유리피판 재건, 특히 피판을 절제 부위에 삽입하기 위해 필요한 과정일 수도 있다. 하지만 이러 한 침습적인 술식은 정상조직을 손상시켜, 술후 많은 합병증 을 유발할 수 있으며, 수술 및 술후 항암/방사선치료 후 기능 적인 저하로 이어질 수 있다. ${ }^{4)}$ 따라서 최근 많은 두경부외과의 들은 이러한 침습적인 술식보다는 경구강술식(transoral approach)을 포함한 다양한 최소 침습 술식(minimally invasive procedure)을 선호한다. ${ }^{5}$

최소 침습 술식을 이용한 절제 후 결손 부위는 유리피판을 이용한 재건 시 기술적인 어려움, 특히 피판을 삽입하는 과정 의 어려움을 유발한다. 두경부의 좁고, 깊은 결손부위의 경우, 피판을 정확하게 위치시켜 봉합하기가 어려우며, 피판과 점막 의 절제연을 정확하게 맞추어 봉합하지 못해 치유가 지연될 
수 있다. 또한 수술과정에서의 과도한 조작(repeated flap manipulation) 및 과신전이 발생할 수 있으며, 혈관경을 위치시 키거나 혈관문합을 시행할 때 ㄲㄲㄲ이거나 손상을 줄 수도 있다.

“패러슈트" 기법은 심장혈관외과 수술 시 사용되는 봉합기 법으로 혈관이나 판막치환술 시 좁은 수술 부위에서 정확한 봉합을 위해 사용된다. ${ }^{6.7)}$ 패러슈트 기법은 혈관이나 봉합할 절개의 부위가 깊은 경우 사용되는데, 여러 바이트(bite)를 위 치시킨 후 결찰하지 않은 상태로 먼저 놔두고 진행하며, 여러 개의 바이트를 봉합할 두 개의 혈관에 위치시킨 후 두 개의 혈관이 낙하산처럼 절개부로 내려오면서 맞도록 디자인하여 양쪽 끝을 동시에 잡아당겨 봉합하게 된다. ${ }^{8)}$

이에 저자는 패러슈트 기법을 활용한 두경부 유리피판 재 건수술, 특히 피판을 좁고, 깊은 결손부위에 위치시킬 수 있 는 재건수술의 준비와 수술 과정을 저자의 경험과 함께 소개 하고자 한다.

\section{방 법}

결손부위 봉합(Suture through the edge of surgical defect)

경부림프절 절제술(neck dissection) 및 두경부암 원발부위 절제술을 마치고 나면 유리피판을 거상하기 전 결손부위 봉 합을 시작하게 된다. 허혈시간(ischemic time)을 줄이기 위해 피판거상 전 절제연의 봉합을 먼저 시행한다. 절제연의 점막 (mucosal edge of surgical defect)을 바늘을 분리할 수 있는 3-0 흡수성 봉합사(vicryl ${ }^{\circledR} 3-0$ pop-off suture)를 이용하여 바이트(bite)를 시행한 후 모스키토 클램프(mosquito surgical clamp) 등을 이용하여 고정해둔다(Fig. 1A and Supplementary Video 1). 이때 실(string)의 순서가 바뀌지 않도록 주의해야 한다. 보통 좌우를 나누어 봉합사들을 두 개 혹은 세 개의 그룹으로 나누어 고정해두는 것이 나중에 피판을 삽 입할 때 구분이 용이하며 봉합사의 바늘이 떨어지지 않도록 주의한다(Fig. 1B). 이후 계획된 유리 피판의 거상을 시작한다.

피판 삽입 및 봉합(Flap inset and suture through the flap)

피판을 거상한 이후, 피판을 두경부 결손부위에 위치시킨 다. 혈관경(pedicle)을 문합할 혈관부위, 상갑상동맥(superior thyroidal artery)이나 안면동맥(facial artery) 등 주변에 위치 시킨 후 피판과 결손부위의 봉합을 시작한다. 이미 결손부위 에 위치한 봉합사를 순서에 맞추어 피판에 바이트를 한 이후 봉합사의 바늘을 당겨서 제거하고, 다시 한 번 순서에 맞추어 모스키토 클램프를 이용해 고정한다(Fig. 2 and Supplemen-

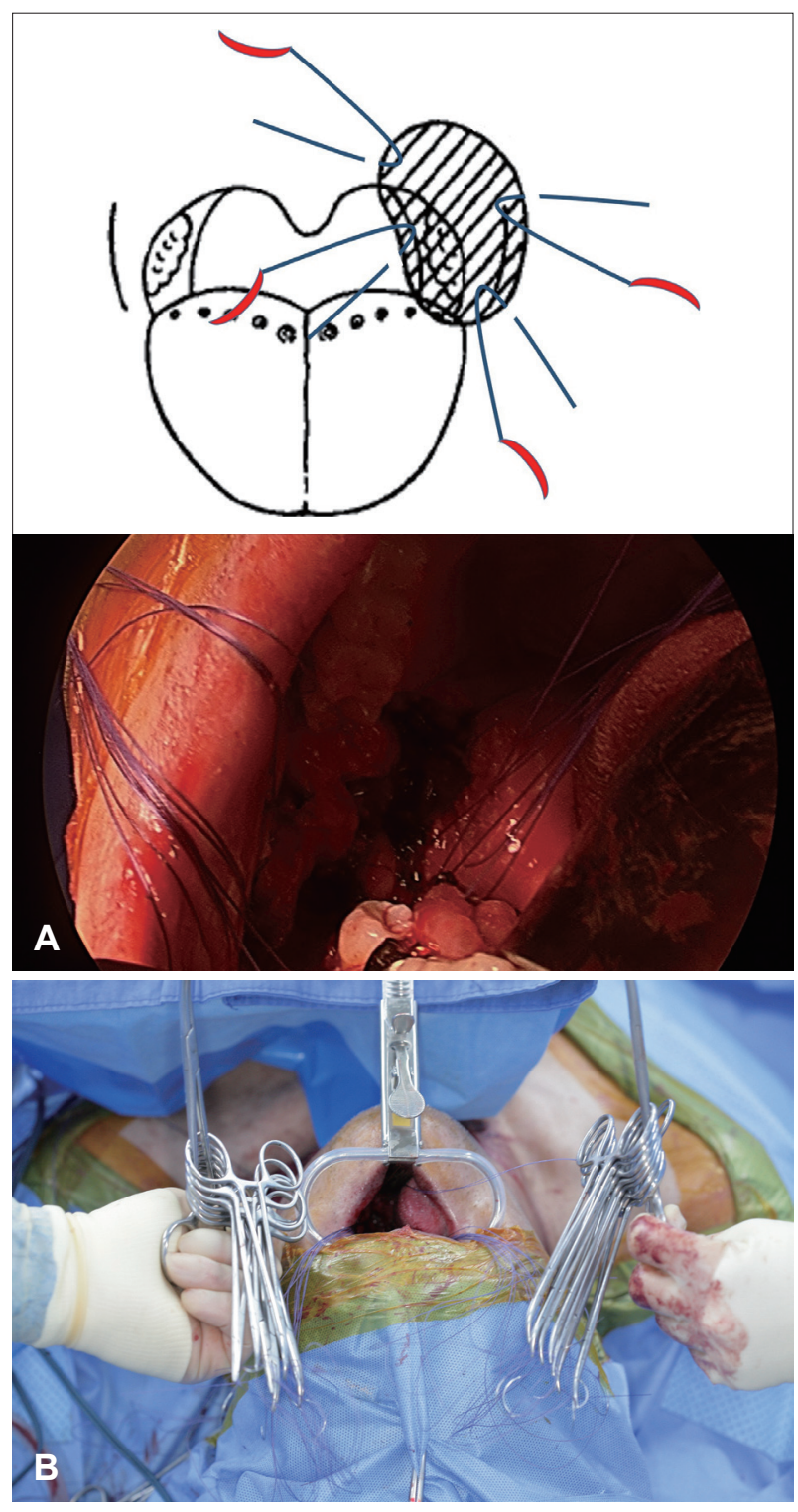

Fig. 1. A: Sequential suture on surgical defect (area of oblique line: surgical defect). B: Grab suture strings with mosquito clamps.

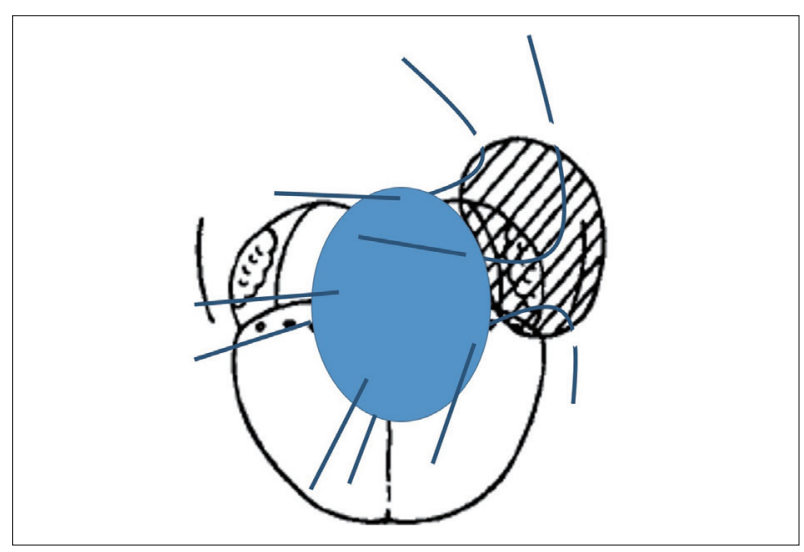

Fig. 2. Suture with a harvest flap defect (area of oblique line: surgical defect, area of blue color: harvest flap). 

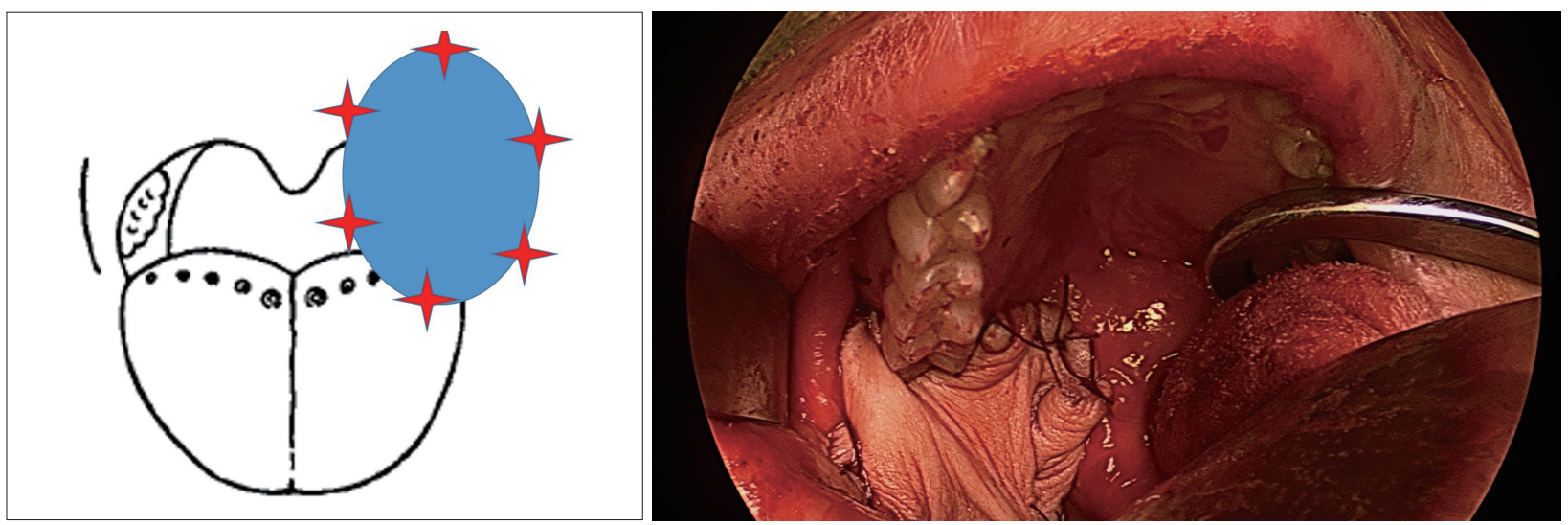

Fig. 3. Tie the knots manually (area of blue color: harvest flap, red asterisk; manually tied knots).

tary Video 1). 이때 봉합은 구강 바깥의 넓은 공간에서 피판 의 적절한 위치를 안전하게 확인한 후 시행할 수 있다. 모든 봉합사의 바이트를 시행한 이후에 봉합사의 결찰 단계로 진 행한다. 이때 역시 실의 순서 및 좌우가 혼동되지 않도록 잘 구분해 두는 것이 매우 중요하다.

봉합사 결찰(Tie the knot of unlocked strings)

구강 바깥쪽 넓은 공간에서 봉합을 시행한 피판을 결손부 위로 적절하게 밀어 넣은 이후 순서대로 결찰하지 않은 봉합 사의 결찰을 순차적으로 시행한다. 이미 절제연과 피판의 바 이트는 적절한 위치에 위치시켰으므로 결찰은 시야에서 정확 하게 확인하지 않고 진행해도 무방하다. 보통 가장 안쪽, 아래 쪽 봉합사부터 결찰을 시행하며, 수술기계를 이용한 결찰보다 는 양손을 이용한 결찰(tie the knot)이 빠르고 정확하게 진행 할 수 있다(Fig. 3 and Supplementary Video 1). 이때도 봉 합사의 순서가 바뀌지 않도록 주의해야 하며, 실이 엉키는 것 도 주의해야 한다. 이후 봉합이 부족한 부분의 봉합을 추가로 시행하면 피판 삽입을 끝내고 미세혈관 유합술(microvascular anastomosis)로 진행할 수 있다.

\section{결 과}

패러슈트 기법은 좁고 깊은 결손에 피판을 삽입하는 데 효 과적인 수술기법이다. 특히 최근 두경부재건에 많이 사용되 는 전외대퇴피판(anterolateral thigh free-flap) 같이 부피가 큰 피판도 효과적으로 빠른 시간 안에 삽입할 수 있다. 수술 시야가 충분히 확보되지 않은 경우에도 안전하고 빠르게 피 판의 삽입을 진행할 수 있는 술기 중 하나이다.

\section{Supplementary Video Legend}

Video 1. Parachute technique for radial forearm free-flap inset to retromolar trigone defect.

\section{Supplementary Materials}

The Data Supplement is available with this article at https://doi. org/10.3342/kjorl-hns.2021.00668.

\section{Acknowledgments}

None.

\section{Author Contribution}

Conceptualization: Yoo Seob Shin. Methodology: Ju Ho Lee. Resources: Yong Jae Song. Writing—original draft: Se Hyun Yeou. Writing — review \& editing: Yoo Seob Shin.

\section{ORCID}

Yoo Seob Shin Tttps://orcid.org/0000-0002-2007-1100

\section{REFERENCES}

1) Sweeny L, Rosenthal EL, Light T, Grayson J, Petrisor D, Troob $\mathrm{SH}$, et al. Outcomes and cost implications of microvascular reconstructions of the head and neck. Head Neck 2019;41(4):930-9.

2) Won HR, An JY, Lee JJ, Kim DY, Jang JY, Kim CH, et al. The effectiveness of an enhanced recovery after surgery protocol in head and neck cancer surgery with free-flap reconstruction. Ann Surg Treat Res 2019;97(5):239-44.

3) Nabil S, Nazimi AJ, Nordin R, Hariri F, Mohamad Yunus MR, Zulkiflee AB. Mandibulotomy: An analysis of its morbidities. Int J Oral Maxillofac Surg 2018;47(12):1511-8.

4) Paderno A, Piazza C, Bresciani L, Vella R, Nicolai P. Microvascular head and neck reconstruction after (chemo)radiation: Facts and prejudices. Curr Opin Otolaryngol Head Neck Surg 2016;24(2):83-90.

5) Finegersh A, Holsinger FC, Gross ND, Orosco RK. Robotic head and neck surgery. Surg Oncol Clin N Am 2019;28(1):115-28.

6) Zannis K, Mitchell-Heggs L, Di Nitto V, Kirsch ME, Noghin M, Ghorayeb G, et al. Correction of anterior mitral prolapse: The parachute technique. J Thorac Cardiovasc Surg 2012;143(4 Suppl): S24-8.

7) Liu CJ, Fang KH, Chang CC, Lin ET, Chang GH, Shen JH, et al. Application of "parachute" technique for free flap reconstruction in advanced tongue cancer after ablation without lip-jaw splitting: A retrospective case study. Medicine (Baltimore) 2019;98(33): e16728.

8) Mousavi SA, Yildirim MEC, Kleppe KES, Chen HC. How to perform a safe, quick, and easy suture technique for microvascular anastomosis, where a single surgeon works alone: The parachute technique. Facial Plast Surg 2020;36(6):778-80. 